\title{
ESPECIFICAÇÃO E IMPLEMENTAÇÃO DE UM PROTÓTIPO PARA GERENCIAMENTO DE PROJETOS
}

\author{
S. F. CEZÁRIO ${ }^{1}$, L. F. de SOUZA ${ }^{2}$, G. M. $\operatorname{COSTA}^{3}$ e F. A. P. de PAIVA ${ }^{4}$ \\ 1, 2,3,4 Instituto Federal do Rio Grande do Norte - Campus João Câmara \\ sidemar_r7@hotmail.com - luizfer_souza@hotmail.com - \\ giovane_cst@yahoo.com.br - fabio.procopio@ifrn.edu.br
}

Artigo submetido em fevereiro/2012 e aceito em julho/2013

\section{RESUMO}

A popularização da Internet tem propiciado uma melhoria na forma de como as pessoas realizam compras, obtêm informação, divulgam seus serviços, além de uma série de outras vantagens. De acordo com essa tendência, a área de Pesquisa e de Extensão do Instituto Federal de Educação, Ciência e Tecnologia do Rio Grande do Norte também utiliza a rede mundial de computadores para divulgação de eventos, de editais de projetos, de cursos de capacitação, etc. Contudo, este setor tem se deparado com alguns elementos que dificultam a operacionalização de suas atividades. Assim, com a finalidade de oferecer-lhe uma melhoria na execução de suas tarefas, este trabalho tem como objetivo o desenvolvimento de um protótipo para gerenciar os projetos do câmpus. O trabalho pode ser considerado satisfatório porque, segundo opiniões de usuários, atende aos seus principais requisitos.

PALAVRAS-CHAVE: IFRN, Pesquisa, Extensão, gerenciamento de projetos.

\section{SPECIFICATION AND IMPLEMENTATION OF A PROTOTYPE FOR PROJECT MANAGEMENT}

\section{ABSTRACT}

The Internet popularization has propitiated an improvement in how people make purchases, obtain information, disseminate their services and a number of other advantages. According to this trend, the Research and Extension department of Instituto Federal de Educação, Ciência e Tecnologia do Rio Grande do Norte also uses the World Wide Web to divulge events, project notices, training courses, etc. However this department has been faced with some elements which hinder the operationalization of its activities. Thus, in order to provide an improvement in the execution of department' tasks, this paper aims to develop a prototype to manage projects on campus. According to users, the work may be considered satisfactory because meets their main requirements.

KEYWORDS: IFRN, Research, Extension, projects management. 


\section{ESPECIFICAÇÃO E IMPLEMENTAÇÃO DE UM PROTÓTIPO PARA GERENCIAMENTO DE PROJETOS}

\section{INTRODUÇÃO}

No final da década de 90, a Internet mudou a maneira de as pessoas trabalharem, de se comunicarem, de se educarem, de se socializarem e de se informarem sobre os mais modernos e diversos assuntos da atualidade (PETRILIS, 2011). O uso da Internet, como sistema de comunicação e forma de organização, vem crescendo significativamente, sendo que, no final de 1995, o primeiro ano de uso disseminado da World Wide Web (WWW), havia cerca de seis milhões de usuários conectados à rede. No início de 2001, eles já eram mais de quatrocentos milhões (CASTELLS, 2003). Segundo o Royal Pingdom, em dezembro de 2009, existiam 234 milhões de websites e, em setembro daquele mesmo ano, 1,73 bilhões de usuários na rede. Já em agosto de 2010, de acordo com a WorldWideWebSize.com, existiam, pelo menos, 14,5 bilhões de páginas indexadas.

Os Institutos Federais de Educação, Ciência e Tecnologia, considerados referências educacionais no país, também estão inseridos nessa revolução tecnológica que abrange inúmeros usuários web. No Rio Grande do Norte, o Instituto Federal tem mais de 100 anos de história e atualmente conta com 16 câmpus. O IFRN tem como função social promover educação científicotecnológico-humanística visando a formação integral do profissional-cidadão (IFRN, 2011), na busca pela competência técnica que permeia todos os níveis de ensino oferecidos desde a formação inicial e continuada de trabalhadores, à formação profissional de nível médio (integrados e subsequentes) e superior (licenciaturas, cursos de tecnologia e pós-graduação).

O Instituto Federal do RN conta com várias áreas que ajudam na qualificação do ensino, entre elas destaca-se o setor de Pesquisa e Extensão que tem como uma das principais características o compromisso social (MARTINS, 2005). No câmpus João Câmara, durante entrevistas com a coordenação daquele setor, foram identificados alguns fatores que dificultam a operacionalização de suas atividades. Alguns desses fatores são a falta de informação sobre a) projetos que estão sendo realizados, b) alunos e professores envolvidos em atividades de pesquisa e de extensão, c) participação da comunidade nos eventos realizados no câmpus, etc.

Assim, este trabalho tem como objetivo desenvolver um protótipo de um Sistema de Gerenciamento de Projetos (SIGEP), que tem como finalidade auxiliar os usuários do setor de Pesquisa e Extensão em suas atividades rotineiras. O trabalho está organizado da seguinte forma: a seção Objetivo descreve os objetivos gerais e específicos do trabalho; na seção seguinte, são apresentadas as demandas identificadas durante o processo de análise de requisitos; na seção Projeto, são apresentados os diagramas de Entidade-Relacionamento e de Classe propostos; na seção Implementação, são discutidas as principais funcionalidades do protótipo e, por fim, na última seção, são apresentadas as conclusões do trabalho.

\section{OBJETIVOS}

De uma forma geral, este trabalho consiste no desenvolvimento, ainda em nível de protótipo, de um Sistema de Gerenciamento de Projetos com a finalidade de auxiliar as atividades dos usuários do setor de Pesquisa e Extensão do IFRN no câmpus João Câmara. De uma forma mais detalhada, o projeto tem como principais objetivos: 
- Informatização dos cadastros de alunos, de servidores e de projetos;

- Melhor gerenciamento dos projetos do câmpus;

- Facilidade na emissão de relatórios de alunos bolsistas;

- Verificação de alunos e professores envolvidos em projetos;

- Listagem de projetos por situação e;

- Relatórios de eventos cadastrados.

\section{ANÁLISE DE REQUISITOS}

Segundo a literatura (PRESSMAN, 2010), compreender os requisitos de um usuário é uma das tarefas de maior dificuldade encontrada por uma equipe de desenvolvimento de software. Portanto, a etapa de levantamento de requisitos é de extrema importância para que seja construído um produto de boa qualidade.

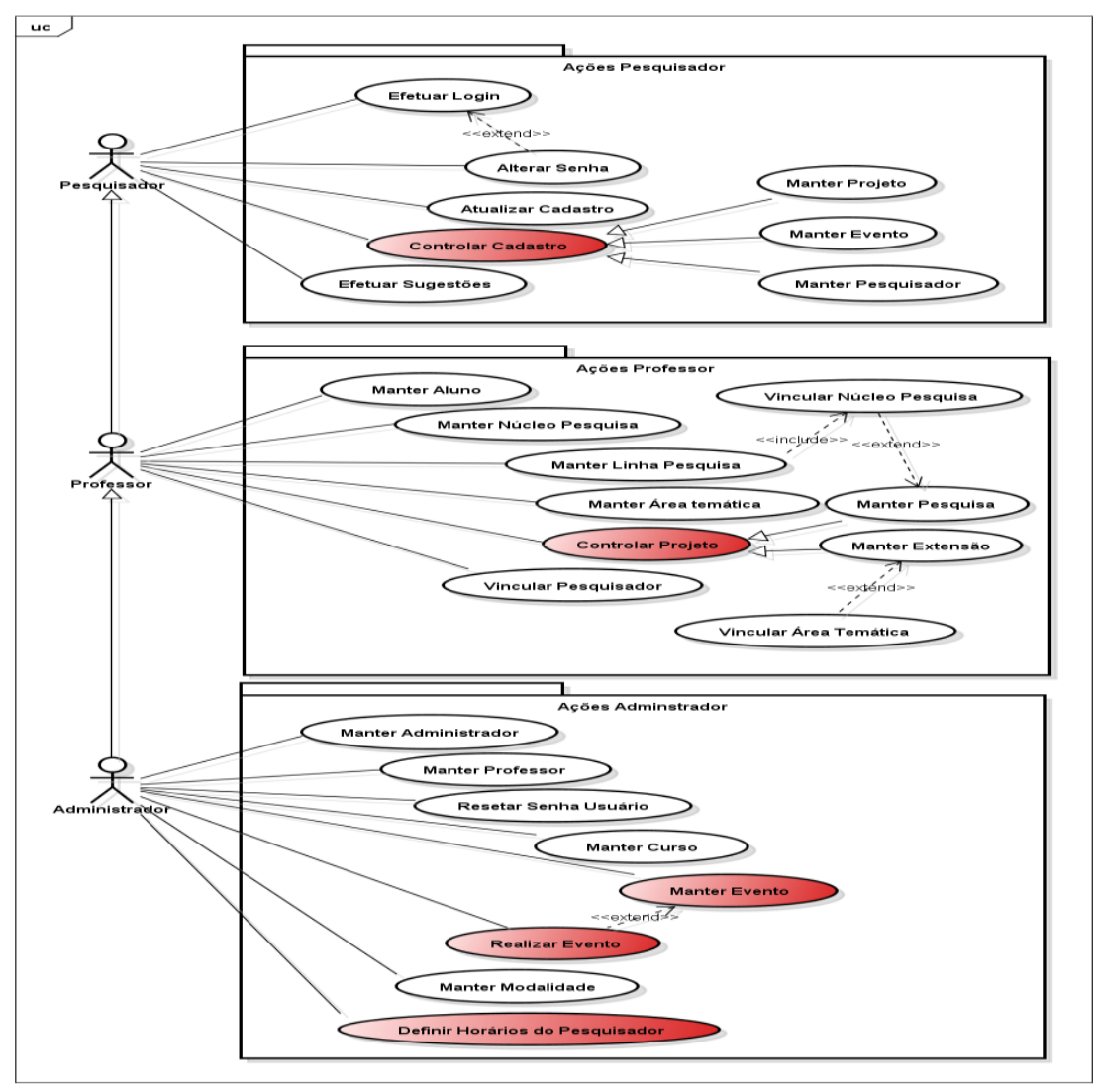

Figura 1 - Diagrama de Caso de Uso

Neste trabalho, a técnica utilizada para identificar os requisitos dos usuários foi a entrevista por ser um procedimento simples e eficaz, sendo muito utilizada na fase inicial do levantamento de requisitos. A Figura 1 apresenta os casos de uso identificados durante as entrevistas realizadas com os usuários. A fim apresentar com mais detalhes o funcionamento dos casos de uso de maior risco, destacados em vermelho na Figura 1, abaixo cada um deles são especificados:

- Controlar Cadastro - o caso de uso começa quando o ator solicita as informações pertinentes a um Projeto, a um Pesquisador ou a um Evento. Para recuperar um conjunto de informações relacionadas a um Aluno, por exemplo, basta informar a sua 
matrícula. O sistema pesquisa essa matrícula no banco de dados e se não for localizada, é exibida a seguinte mensagem: "Matrícula não encontrada!". Caso contrário, o formulário que contém os dados do aluno é preenchido. A sequência para recuperar informações do Professor ou de um Evento é semelhante a esta.

- Controlar Projeto - este caso de uso começa quando o ator deseja inserir ou atualizar dados de um Projeto. $O$ ator informa os parâmetros necessários para localizar o Projeto. O sistema verifica se existe algum registro com os parâmetros informados, em caso negativo, é exibida a mensagem "Nenhum Projeto foi localizado!". Caso contrário, um formulário é preenchido com os dados do Projeto. Em seguida, o ator altera esses dados e o sistema, por sua vez, confirma a alteração no banco de dados e exibe a mensagem "Operação realizada com sucesso!".

- Manter Evento - o caso de uso começa quando o ator deseja cadastrar um Evento. O ator informa os parâmetros necessários e o sistema verifica se o evento já está registrado. Em caso negativo, é exibida a mensagem "Nenhum Evento foi localizado!". Caso contrário, o formulário com os dados do Evento é preenchido. Quando o ator confirmar a operação, os dados são inseridos no banco de dados e é exibida a seguinte mensagem: "Operação realizada com sucesso!". A sequência típica do caso de uso Realizar Eventos é semelhante a esta.

- Definir Horário Pesquisador - este caso de uso começa quando o ator informa os dados e os horários de atuação do Pesquisador, bem como o Projeto ao qual ele está envolvido. 0 ator informa os parâmetros necessários para localizar um Projeto. O sistema faz uma verificação e se nenhum Projeto for localizado com os parâmetros informados, é exibida a mensagem "Nenhum Projeto foi localizado!". Caso contrário, um formulário é preenchido com os dados referentes. $O$ ator informa os parâmetros necessários para localizar um Pesquisador. Se o sistema não localizar nenhum registro, é exibida a mensagem "Nenhum Pesquisador foi localizado!". Caso contrário, o formulário é preenchido com os dados do Pesquisador. Para finalizar, basta o ator confirmar os dados relacionados ao Pesquisador e ao Projeto.

\section{PROJETO}

Os requisitos elicitados anteriormente se tornaram fundamentais para a especificação do nosso protótipo. A seguir, serão apresentadas algumas tabelas do Diagrama de Entidade Relacionamento (DER). 


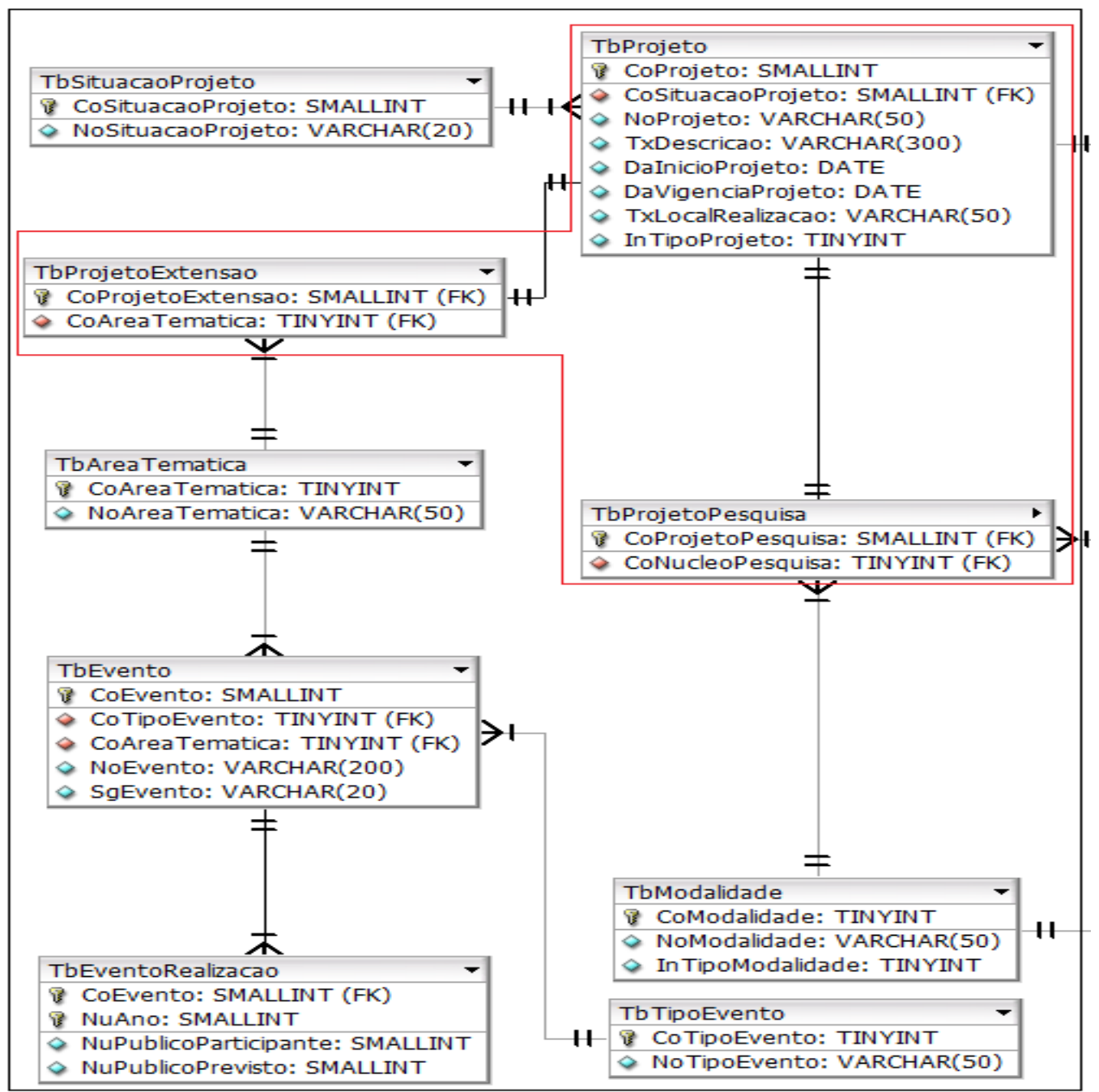

Figura 2 - Especialização de TbProjetoPesquisa e TbProjetoExtensao a partir de TbProjeto.

Nas tabelas TbProjetoExtensao e TbProjetoPesquisa acontece uma generalização/especialização. As duas tabelas compartilham atributos de TbProjeto (NoProjeto, DalnicioProjeto e outros). Contudo, possuem atributos que são exclusivos de cada uma (e.g., CoAreaTematica) na TbProjetoExtensao e (e.g., CoNucleoPesquisa) como atributo da tabela TbProjetoPesquisa.

Além do DER, também foi construído um Diagrama de Classe. Para melhor entendê-lo, foi utilizada a UML em Cores, uma técnica de modelagem que utiliza quatro cores para facilitar a identificação das classes em um diagrama (MEDEIROS, 2011):

- Rosa - representa entidades que possuem um tempo de vida bem definido (por exemplo, pedido de venda, processo de matrícula, etc);

- Amarelo - simboliza uma entidade que com um papel muito bem definido na aplicação (por exemplo, cliente, funcionário, etc);

- Verde - representa qualquer entidade que seja uma pessoa (física ou jurídica) ou algum lugar (departamento, cidade, país, etc) ou alguma coisa (produtos, tributo, etc);

- Azul - simboliza entidades fracas que servem como meta-informações para outras entidades (por exemplo, status, estado civil, etc). 


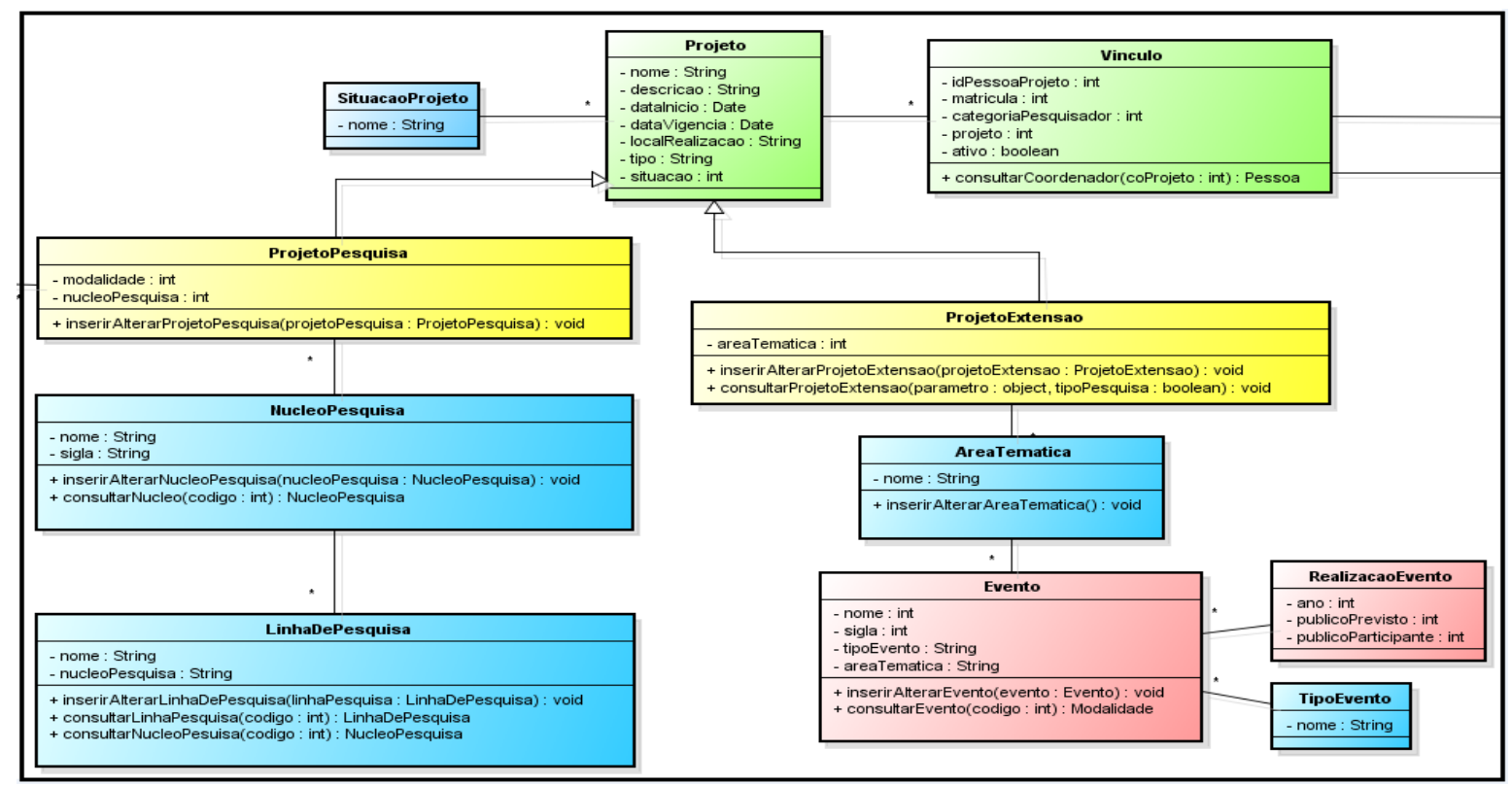

Figura 3 - Fragmento do Diagrama de Classes

Abaixo segue a descrição das principais classes do sistema:

- Vínculo - responsável por relacionar os projetos com as pessoas. A partir dessa classe é possível obter informações importantes como: quantas pessoas estão em determinado projeto, quem é o coordenador do curso, número de desistentes, etc.

- Projeto - gerencia projetos de forma generalizada, contendo informações em comum de Projetos de Pesquisa e de Extensão.

- ProjetoPesquisa - reúne informações sobre modalidade e núcleo de pesquisa.

- ProjetoExtensao - é utilizada sempre que for preciso alterar, cadastrar ou consultar os projetos de extensão.

- Evento - proporciona o gerenciamento de eventos.

- EventoRealizacao - registra informações sobre ano de realização do evento, público previsto e público participante.

- NucleoPesquisa - gerencia informações sobre núcleos de pesquisa.

- LinhaDePesquisa - Exerce a função de organizar as linhas de pesquisa em núcleos de pesquisa, permitindo facilidade na consulta das mesmas.

\section{IMPLEMENTAÇÃO}

Depois da análise de requisitos e da especificação do protótipo, apresentadas anteriormente, serão expostos, alguns aspectos utilizados na implementação. Para o desenvolvimento foi utilizado o padrão de arquitetura de software MVC (Model-view-controller). O padrão objetiva organizar e facilitar a interação dos componentes da aplicação. Na arquitetura do sistema também temos o DAO (Data Access Object), um padrão de software usado em engenharia de software, que consiste em abstrair o mecanismo de persistência utilizado na aplicação. Por fim, a linguagem de programação utilizada foi a PHP e o SGBD o SQL Server 2008, versão Express. 


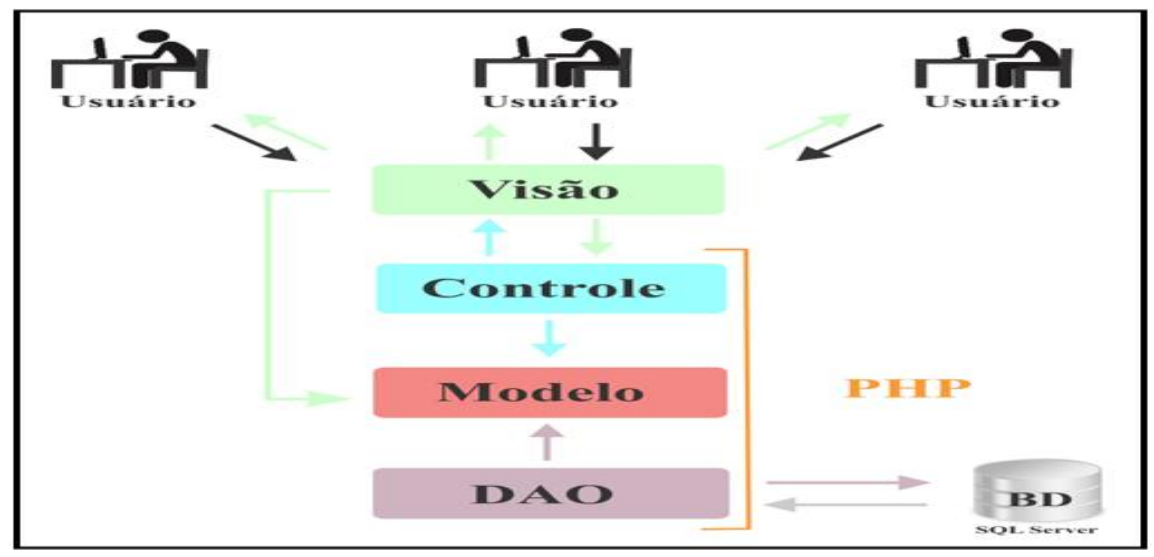

Figura 4 - Arquitetura do Sistema

O controle de fluxo do padrão MVC funciona como segue abaixo: 1) o usuário interage com a interface clicando em um botão, 2) o controle manipula o evento da interface do usuário usando uma rotina pré-escrita, 3) o controle acessa o modelo, atualizando-o de uma maneira apropriada, baseado na interação do usuário, por exemplo, atualizando os dados de Cadastro do Aluno, 4) algumas implementações da visão utilizam o modelo para gerar uma interface apropriada, por exemplo, mostrando na tela os dados que foram alterados juntamente com uma confirmação e 5) a interface do usuário espera pelas próximas interações que iniciarão um novo ciclo.

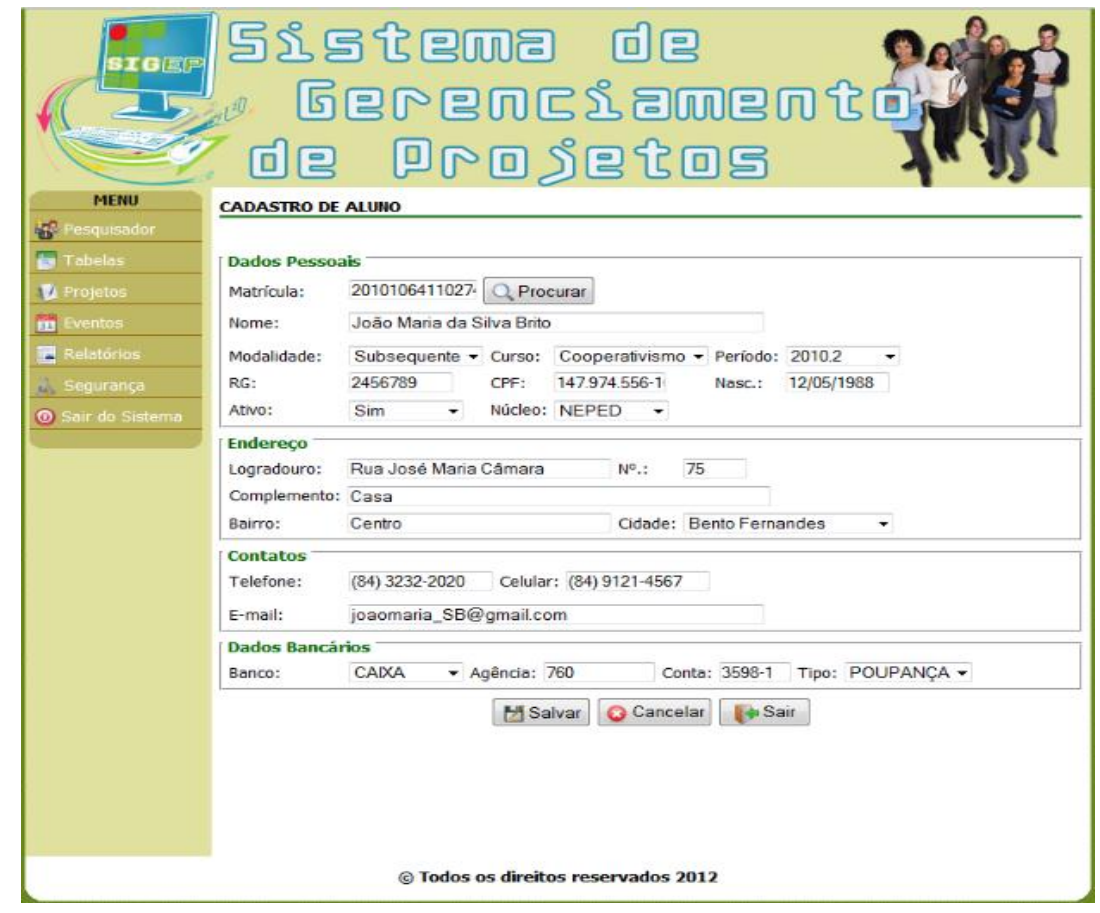

Figura 5 - Página de Cadastro de Aluno 


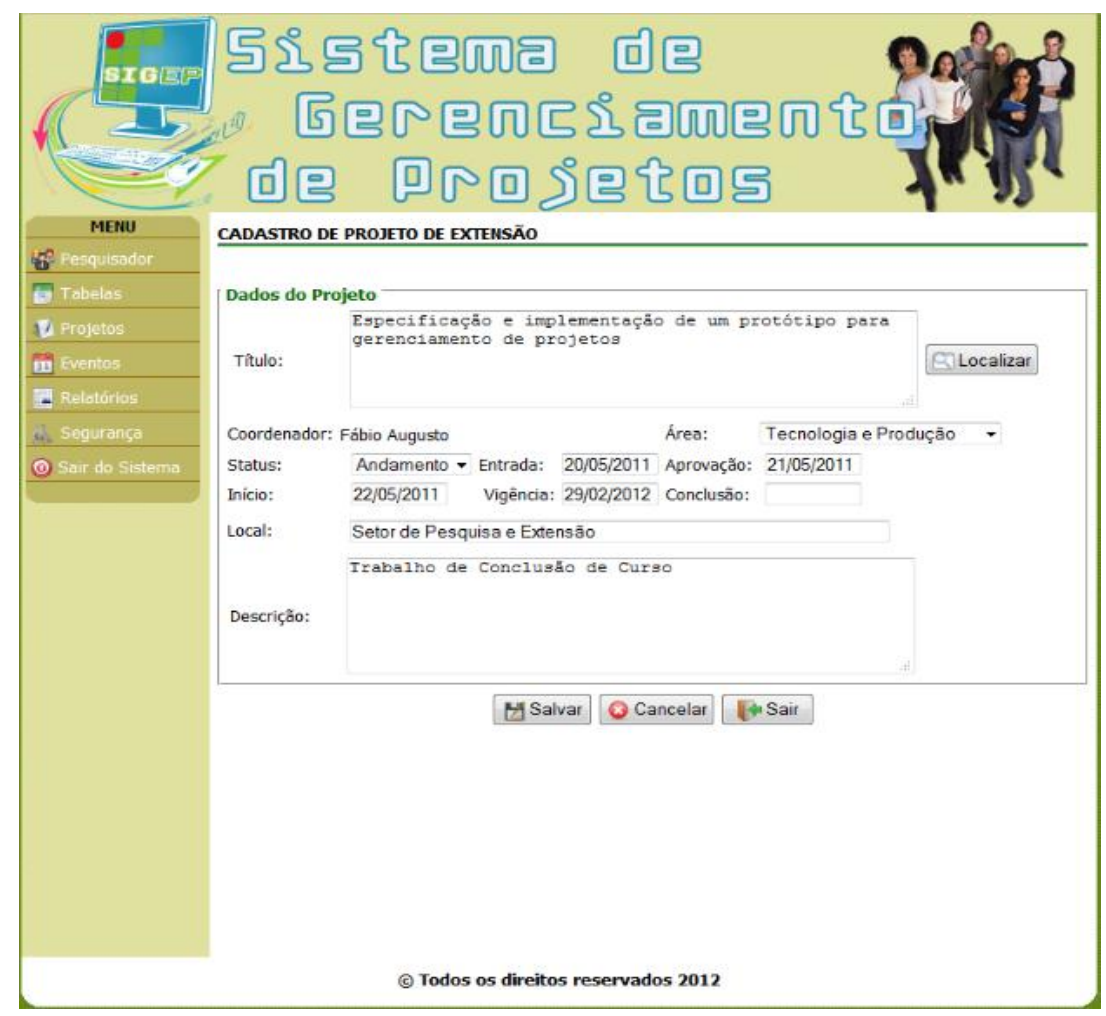

Figura 6 - Página de Cadastro de Projeto de Extensão

A Figura 5 apresenta a página de Cadastro de Aluno, na qual o Administrador do sistema ou um Professor poderá cadastrar ou consultar Alunos. $O$ usuário tem acesso a esta página, clicando no menu Pesquisador e selecionando o subitem Aluno, que aparecerá ao lado. 0 cadastro de Professor é semelhante ao de Aluno.

A Figura 6 representa o Cadastro de Projetos de Extensão. A partir dela, um Administrador ou um Professor pode cadastrar projetos. O usuário terá acesso à página clicando no menu Projetos e selecionando o subitem Projeto de Extensão. O Cadastro de Projeto de Pesquisa também é similar ao de Projeto de Extensão. 


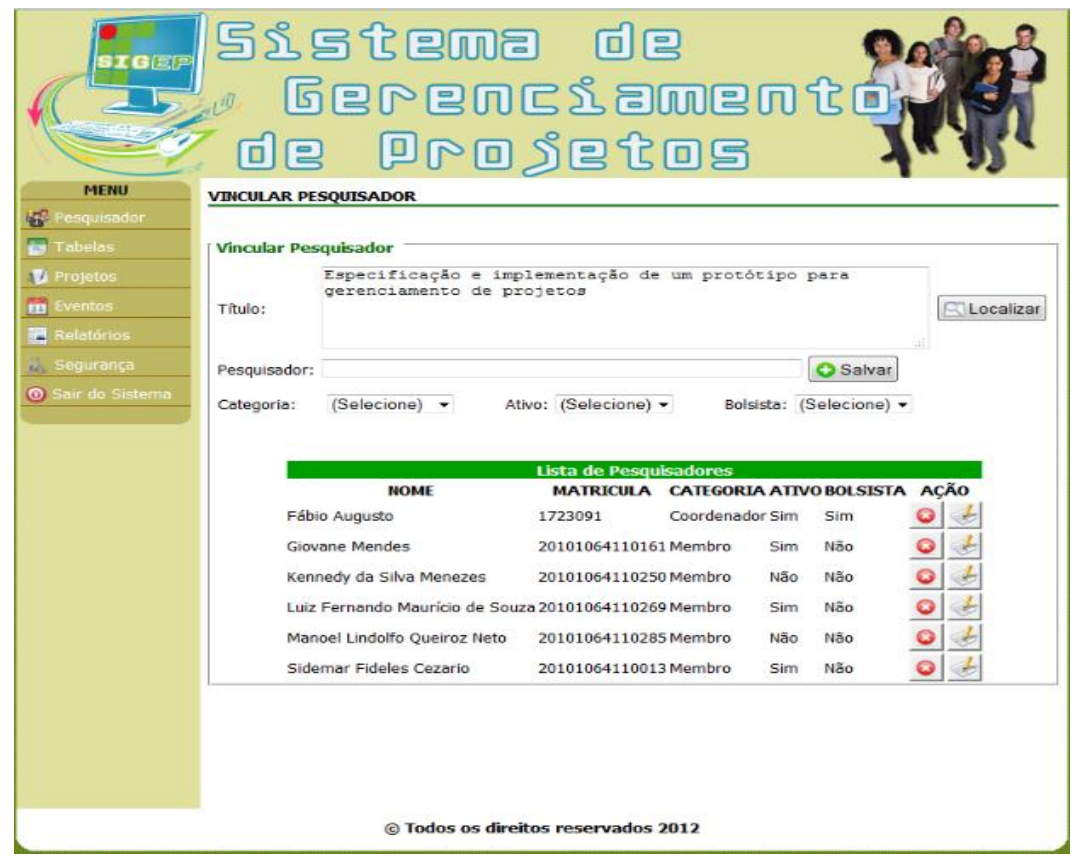

Figura 7 - Página de Vincular Pesquisador

Por fim, a Figura 7 apresenta a página que permite a efetivação de um vínculo entre um Pesquisador e um Projeto, a qual pode ser realizada por um Administrador ou um Professor. Para utilizar esta funcionalidade, basta o usuário acessar o menu Projetos $\rightarrow$ Pesquisador.

\section{CONCLUSÕES}

Este trabalho apresenta um protótipo de um sistema para gerenciamento de projetos do setor de Pesquisa e Extensão do IFRN, câmpus João Câmara. Apesar das dificuldades encontradas durante a sua construção, o resultado obtido é considerado satisfatório levando em consideração os testes que foram realizados pelos usuários e por atender às necessidades do cliente, como: i) listagem de projetos, ii) relatório de alunos e de professores envolvidos em projetos, iii) listagem da situação de projetos, iv) relatório de alunos bolsistas e, v) listagem de eventos realizados no campus.

Os coordenadores e bolsistas do setor de Pesquisa e Extensão se dispuseram a realizar novas avaliações a fim de sugerir mudanças para posterior implantação. Como trabalhos futuros, é importante que novas implementações sejam realizadas. Uma delas é o controle de acesso ao sistema utilizando perfis. Para isso, é necessário: a) permitir a criação de perfis de acesso, b) associar cada página do sistema a um transação, c) vincular usuários a um (ou mais) perfil(s) cadastrado(s) e, d) vincular transações a perfis de acesso. Além disso, nós pretendemos criar um módulo que a) permita o agendamento de visitas a locais de projetos de pesquisa/extensão e b) emita certificados de eventos realizados no câmpus.

\section{REFERÊNCIAS BIBLIOGRÁFICAS}

1. ANTUNES, Jonathan. MVC: O padrão de arquitetura de software. Oficina da Net, 2009. Disponível em:

<http://www.oficinadanet.com.br/artigo/1687/mvc_o_padrao_de_arquitetura_de_softwar e>. Acesso em: 11 dez. 2011. 
2. CASTELLS, Manuel. A Galáxia da Internet: Reflexões sobre a internet, os negócios e a sociedade. Tradução, Maria Luiza X. de A. Borges; revisão técnica, Paulo Vaz. Rio de Janeiro: Jorge Zahar Ed., 2003.

3. IFRN, Portal. Função Social. Disponível em: <http://portal.ifrn.edu.br/institucional/defaultpage> Acessado em 01 de dez. 2011.

4. MARTINS, Lígia Márcia. Ensino-Pesquisa-Extensão como fundamento metodológico da construção do conhecimento na Universidade. Disponível em: <http://www.franca.unesp.br/oep/Eixo\%202\%20-\%20Tema\%203.pdf> Acessado em: 10 nov. 2011.

5. MEDEIROS, Manoel Pimentel. Revista Visão Ágil: Brincando com UML em Cores. Edição 01. $f$ 40.

6. NIEDERAUER, Juliano. Desenvolvendo Websites com PHP. 2. ed. São Paulo: Novatec Editora, 2011.

7. PETRILIS, Dimitris; HALATSIS, Constantin. Combining SOMs and Ontologies for Effective Web Site Mining. 2011.

8. PRESSMAN, Roger S. Engenharia de Software. Mc Graw Hill, 6ed, Porto Alegre, 2010.

9. TANEMBAUM. Andrew S. Redes de Computadores. Tradução por Insight de Informática. 3. Ed. Rio de Janeiro: Campus, 1997.

10. YAMAGUTI, Silvio Yochio. Orientação a Objetos no desenvolvimento de sistemas: Conceitos e características. Brasília: ESAB. 68f. Monografia (Engenharia de Sistema), Escola Superior Aberta do Brasil, 2006.

11. ZANELATO, Ana P. A. ETIC - Encontro de Iniciação Científica: Desenvolvendo Aplicações Web com Ajax. Disponível em <http://intertemas.unitoledo.br/revista/index.php/ETIC/article/viewArticle/2540> Acessado em 31 de jan. de 2012. 